\title{
Study of the Crystallographic and Magnetic Structure in the Nickel Substituted Cobalt Ferrites by Neutron Diffraction
}

\author{
Sadia Khanam1, A. K. M. Zakaria'², M. H. Ahsan1, T. K. Datta'2, S. Aktar², S. I. Liba², \\ S. Hossain², A. K. Das' ${ }^{2}$ I. Kamal' ${ }^{2}$, S. M. Yunus², D. K. Saha ${ }^{3}$, S.-G. Eriksson 4 \\ ${ }^{1}$ Department of Physics, Shahjalal University of Science \& Technology, Sylhet, Bangladesh \\ ${ }^{2}$ Institute of Nuclear Science \& Technology, Bangladesh Atomic Energy Commission, Dhaka, Bangladesh \\ ${ }^{3}$ Atomic Energy Centre, Bangladesh Atomic Energy Commission, Dhaka, Bangladesh \\ ${ }^{4}$ Department of Chemical and Biological Engineering, Chalmers University of Technology, Gothenburg, Sweden \\ Email: zakaria6403@yahoo.com
}

Received 29 January 2015; accepted 17 April 2015; published 21 April 2015

Copyright (C) 2015 by authors and Scientific Research Publishing Inc.

This work is licensed under the Creative Commons Attribution International License (CC BY). http://creativecommons.org/licenses/by/4.0/

(c) (i) Open Access

\section{Abstract}

The polycrystalline spinel oxides $\mathrm{Ni}_{\mathrm{x}} \mathrm{Co}_{1-\mathrm{x}} \mathrm{Fe}_{2} \mathrm{O}_{4}$ with composition $\mathrm{x}=0.0,0.2,0.4,0.6,0.8$ and 1.0 were prepared by conventional solid state ceramic sintering technique in air at $1300^{\circ} \mathrm{C}$. X-ray diffraction experiments were carried out on all the samples at room temperature in order to characterize the materials. X-ray diffraction patterns showed sharp peaks indicating the formation of single phase cubic spinel structure. The neutron diffraction experiments were performed on all samples at room temperature, with an incident monochromatic neutron beam of wavelength $\lambda=$ $1.5656 \AA$. The experimental neutron diffraction data were analyzed using the computer program FullProf in the Reitveld method. Reitveld refinement of the neutron diffraction data reveals that the samples possess cubic symmetry corresponding to the space group $F \mathrm{~d}-3 \mathrm{~m}$. Cation distribution between the two sublattices of the spinel structure has been found from the analysis of the neutron diffraction data. Lattice parameters, oxygen position parameters, and overall temperature factors have also been determined from the analysis of neutron diffraction data. The lattice parameter decreases and oxygen position parameter increases with increasing $\mathrm{Ni}$ content in the system. Sublattices and net magnetic moments have been determined from the refinement of neutron diffraction data. The magnetic structure at room temperature was found to be ferrimagnetic for all the samples.

\section{Keywords}

Ferrites, Spinel Structure, Crystal Structure, Neutron Diffraction, Ferrimagnetic

\footnotetext{
${ }^{*}$ Corresponding author.
}

How to cite this paper: Khanam, S., et al. (2015) Study of the Crystallographic and Magnetic Structure in the Nickel Substituted Cobalt Ferrites by Neutron Diffraction. Materials Sciences and Applications, 6, 332-342. 


\section{Introduction}

Spinel oxides have been the subject of great interest because of their wide applications in the high frequency devices [1]-[4]. Spinel ferrite plays an important role in a variety of technical fields such as telecommunication, AC and DC motors, switched mode power supplies, power distribution transformers, communication systems, digital memories, multilayer chip inductors, video and audio applications, radar and satellite communications and in many other technological applications like photoelectrical devices and gas sensors, magneto-mechanical stress and torque sensors, microwave devices and biomedical applications [5]-[7].

The general chemical formula of spinel ferrite is $\mathrm{AB}_{2} \mathrm{O}_{4}$, where $\mathrm{A}$ is a divalent metal ion (cation) and $\mathrm{B}$ is a trivalent metal ion (cation). The oxygen ions form a face centered cubic (fcc) lattice and the cations occupy the interstitial positions. The A cations are located in tetrahedral sites, and the B cations are in octahedral sites. The cubic structure permits to substitute cations selectively in the octahedral or tetrahedral sites or in both the sites. This helps to modify electrical properties and magnetic ordering in these systems. Extensive work has been done by various workers to upgrade the properties of ferrites by substituting different types and amount of impurities [8]-[16].

The physical properties of the spinel ferrites such as the electrical, magnetic and elastic properties are governed by the type of magnetic ions residing on the tetrahedral (A) site and octahedral (B) site of the spinel lattice and the relative strength of the inter- and intra-sublattice interactions [8] [17]. Neutron diffraction, in many cases, can give an unambiguous picture of the cation distribution since in neutron scattering, the adjacent elements in the periodic table, unlike X-ray scattering, are distinguishable [16] [18] [19]. The marked differences in nuclear scattering amplitude of the cations and interaction of their magnetic moments with the neutron magnetic moment make possible the accurate determination of cation distribution and magnetic structure in the spinel system [8] [16] [17] [19].

Cobalt ferrite $\left(\mathrm{CoFe}_{2} \mathrm{O}_{4}\right)$ is a well-known hard magnetic material with remarkably high electrical resistivity, large permeability at high frequency and cost effectiveness. In the present study, Co ions have been substituted by divalent $\mathrm{Ni}$ ions in order to determine the cation distribution, and other crystallographic and magnetic properties in the spinel system $\mathrm{Ni}_{\mathrm{x}} \mathrm{Co}_{1-\mathrm{x}} \mathrm{Fe}_{2} \mathrm{O}_{4}$ using neutron diffraction technique.

\section{Experimental Details}

\subsection{Sample Preparation and Characterization}

A series of ferrite sample $\mathrm{Ni}_{\mathrm{x}} \mathrm{Co}_{1-\mathrm{x}} \mathrm{Fe}_{2} \mathrm{O}_{4}$ with compositions $\mathrm{x}=0.0,0.2,0.4,0.6,0.8$ and 1.0 were prepared by solid state sintering method at the Institute of Nuclear Science and Technology (INST), Atomic energy Research Establishment (AERE), Bangladesh Atomic Energy Commission (BAEC), Savar, Dhaka, Bangladesh. For each of the samples high purity oxides, $\mathrm{NiO}$ (97.36\%), $\mathrm{Co}_{3} \mathrm{O}_{4}(>99 \%), \mathrm{Fe}_{2} \mathrm{O}_{3}(>99 \%)$, were used maintaining exact stoichiometric ratios. The oxide powders were weighed separately and then mixed thoroughly in an agate mortar for 6 hours with a small amount of ethanol. The mixtures were heated in alumina crucible at $800^{\circ} \mathrm{C}$ for 10 hours following the furnace cooling in air. The calcinated samples were again mixed in agate mortar for 2 hours. The samples were then pressed into small pellets using a pellet die of $13 \mathrm{~mm}$ diameter at a pressure of 5 tons using a hydraulic press. A small amount of polyvinyl alcohol (PVA) was added as a binder. The pellets were then heated at a temperature of $1300^{\circ} \mathrm{C}$ in a furnace in air for 8 hours.

$\mathrm{X}$-ray powder diffraction measurements were carried out on all the six samples of the series $\mathrm{Ni}_{\mathrm{x}} \mathrm{Co}_{1-\mathrm{x}} \mathrm{Fe}_{2} \mathrm{O}_{4}(\mathrm{x}=$ $0.0,0.2,0.4,0.6,0.8$ and 1.0 ) at room temperature in order to check their quality and phase purity using an X-ray diffractometer (Phillips PW 3040 X'Pert PRO) with $\mathrm{Cu}(\mathrm{K} \alpha$ ) radiation of wavelength $1.54178 \AA$ at the Atomic Energy Center, BAEC, Dhaka, Bangladesh. The X-ray diffraction patterns recorded in the angular range $15^{\circ} \leq 2 \theta \leq 85^{\circ}$ with a step size of $0.02^{\circ}$. All the diffraction patterns showed sharp peaks corresponding to single phase cubic spinel structure. One such representative X-ray diffraction pattern for $\mathrm{x}=0.4$ is shown in Figure 1 for illustration.

\subsection{Data Collection and Rietveld Refinement}

Neutron powder diffraction experiments were performed on all the specimens at room temperature using a high performance neutron powder diffractometer (SAND) located at radial beam port 2 of the 3MW TRIGA Mark II research reactor at AERE, Savar, Dhaka, consisting of 15 element linear position sensitive detectors filled with 


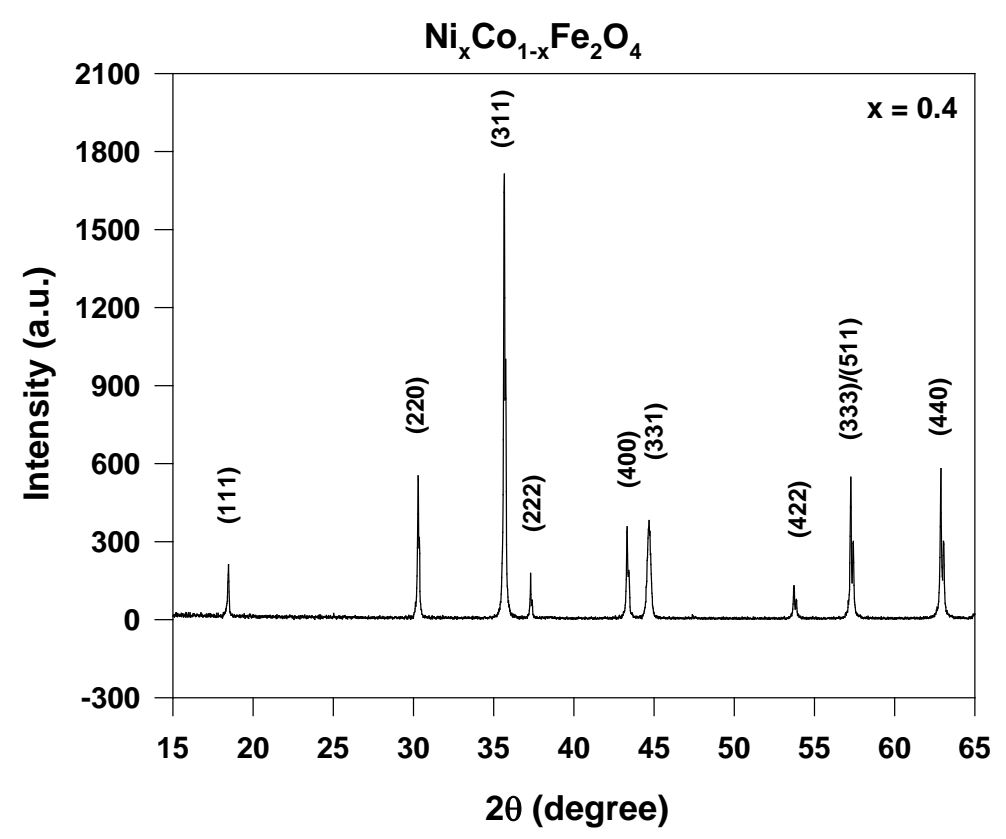

Figure 1. X-ray diffraction pattern for the spinel oxide $\mathrm{Ni}_{\mathrm{x}} \mathrm{Co}_{1-\mathrm{x}} \mathrm{Fe}_{2} \mathrm{O}_{4}$ at $\mathrm{x}=$ 0.4 showing single phase cubic spinel structure.

${ }^{3}$ He gas placed parallel to each other. The diffractometer consists of a doubly bent focusing monochromator made of 9 silicon single crystal slabs of size $0.570 \times 0.210 \times 7.50 \mathrm{in}^{3}$. Monochromatic neutron beam of wavelength $\lambda=1.5656 \AA$ obtained by Bragg reflection from (511) plane corresponding to a take-off angle of $97^{\circ}$ was used in this experiment. Approximately $5 \mathrm{~g}$ of sample of each of the compositions was contained in a cylindrical vanadium can of $6 \mathrm{~mm}$ diameter and $50 \mathrm{~mm}$ height. The neutron flux at the sample position is approximately $10^{5}$ neutrons $\mathrm{cm}^{-2} \cdot \mathrm{s}^{-1}$. The step scan covered a $2 \theta$ range of $10^{\circ}-110^{\circ}$ with a step size of $0.05^{\circ}$.

The refinement of the neutron diffraction data was done using the computer program FullProf [20] in the Rietveld method [21] for determining the crystal structure parameters. In the crystallographic refinement, the higher angle neutron data $\left(2 \theta>50^{\circ}\right)$ were used in the refinement in order to avoid any ambiguity arising from the magnetic contributions from the lower angle data. Because the lower angle Bragg peaks are usually masked with magnetic contributions in spinels, crystallographic and magnetic unit cells and the corresponding symmetries are the same and both the nuclear and magnetic contributions to the Bragg diffraction peaks occur at the same scattering angles. Reitveld refinement of the neutron diffraction data provides a precise determination of the crystal structure in terms of the positions, widths and intensities of the Bragg peaks. Peak asymmetry correction was applied for reflection below $65^{\circ}$ in $2 \theta$. Peak shapes were quantified by a pseudo-Voigt function. In the refinement process the background intensities were refined using a Chebyshev polynomial function with six coefficients. Each structural model was refined to convergence with the best result selected on the basis of agreement factors and stability of the refinement. In the last cycle of the refinement, about 19 parameters were varied including scale factor, zero shift, peak shape parameters, half width parameters, oxygen position parameters, lattice parameters, overall isotropic temperature factors and occupancies. The magnetic structure was refined using the total neutron diffraction data recorded in the $2 \theta$ range $10^{\circ}-110^{\circ}$. The refinement was done with the same software FullProf using two different phases for nuclear and magnetic contributions, respectively.

\section{Results and Discussion}

In the spinel systems, the magnetic unit cell is the same as the crystallographic unit cell having identical symmetry relations. Hence the nuclear and magnetic contribution to the Bragg reflections occurs at the same angular position. Thus the Bragg diffraction peaks in the neutron diffraction data contains both nuclear and magnetic contributions. Due to the strong form dependence of neutrons the magnetic contributions rapidly fall off with scattering angle. Therefore, in order to avoid any ambiguities arising from the magnetic contribution to the Bragg intensities, higher angle neutron diffraction data $\left(50^{\circ} \leq 2 \theta \leq 110^{\circ}\right)$, where the magnetic contribution is 
negligible, were profile analyzed using the computer program FullProf [20] in the Reitveld method [21] for the determination of cation distributions and other crystallographic parameters for all the samples. Figure 2 shows once such representative fitted neutron diffraction pattern confined to higher scattering angle $\left(50^{\circ} \leq 2 \theta \leq 110^{\circ}\right)$ for composition $\mathrm{x}=0.2$, showing an excellent agreement between the observed and calculated profiles in the nuclear phase. The space group $F d-3 m$ was used in the data analysis for generating the calculated profile because the symmetry of the crystal structure of spinel system belongs to this space group. Rietveld agreement factors (R-factors), cation distribution and crystallographic parameters obtained from the refinement of the neutron diffraction data have been summarized in Table 1 .

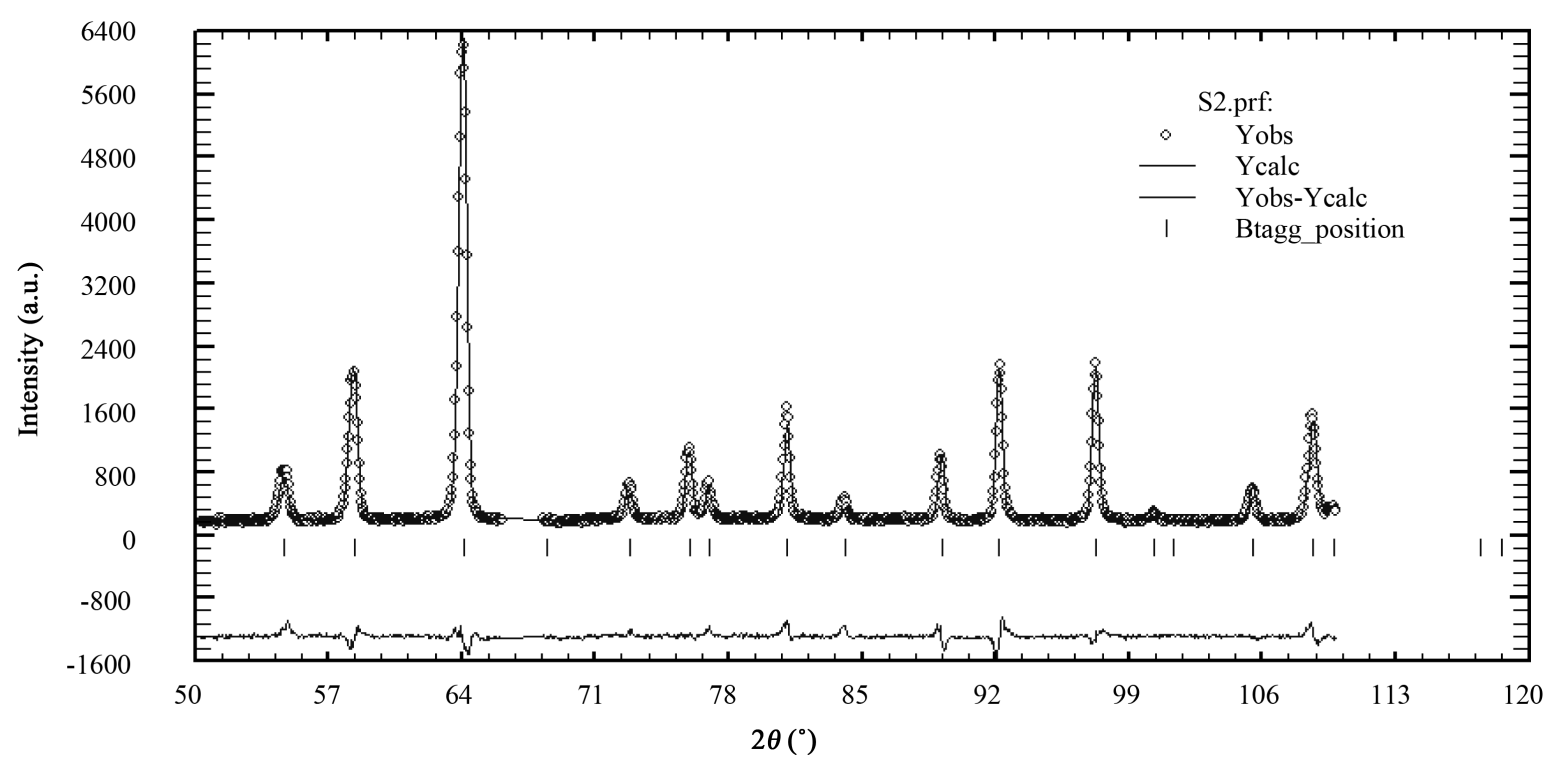

Figure 2. Observed (circles) and calculated (continuous line) higher angle neutron diffraction intensity profiles for $\mathrm{Ni}_{\mathrm{x}} \mathrm{Co}_{1-\mathrm{x}} \mathrm{Fe}_{2} \mathrm{O}_{4}$ at $\mathrm{x}=0.2$ considering only nuclear phase. The short vertical lines indicate the angular position of the allowed Bragg reflections. At the bottom the difference plot, $I_{o b s}-I_{c a l c}$, is shown.

Table 1. Cation distribution, Rietveld agreement factors (R-factors) and crystallographic parameters for the spinel system $\mathrm{Ni}_{\mathrm{x}} \mathrm{Co}_{1-\mathrm{x}} \mathrm{Fe}_{2} \mathrm{O}_{4}$ at room temperature.

\begin{tabular}{|c|c|c|c|c|c|c|}
\hline \multirow{2}{*}{$\mathrm{x}$} & \multicolumn{2}{|c|}{ Cation distribution } & \multirow{2}{*}{$\mathrm{a}_{\text {expt }}(\AA)$} & \multirow{2}{*}{$\mathrm{a}_{\text {calc }}(\AA)$} & \multirow{2}{*}{$\mathrm{B}_{\text {overall }}\left(\AA^{2}\right)$} & \multirow{2}{*}{ R-factors (\%) } \\
\hline & Tetrahedral (A) site & Octahedral (B) site & & & & \\
\hline 0.0 & $\left(\mathrm{Co}_{0.11} \mathrm{Fe}_{0.89}\right)_{\mathrm{A}}$ & {$\left[\mathrm{Co}_{0.89} \mathrm{Fe}_{1.11}\right]_{\mathrm{B}}$} & $8.3599(5)$ & 8.3638 & $0.70(4)$ & $\begin{array}{l}\mathrm{R}_{\text {Bragg }}=3.88 \\
\mathrm{R}_{\mathrm{F}}=2.85 \\
\chi^{2}=2.26\end{array}$ \\
\hline 0.2 & $\left(\mathrm{Co}_{0.05} \mathrm{Fe}_{0.95}\right)_{\mathrm{A}}$ & {$\left[\mathrm{Ni}_{0.2} \mathrm{Co}_{0.75} \mathrm{Fe}_{1.05}\right]_{\mathrm{B}}$} & $8.3445(6)$ & 8.3482 & $0.75(4)$ & $\begin{array}{l}\mathrm{R}_{\text {Bragg }}=5.21 \\
\mathrm{R}_{\mathrm{F}}=3.72 \\
\chi^{2}=2.91\end{array}$ \\
\hline 0.4 & $\left(\mathrm{Co}_{0.03} \mathrm{Fe}_{0.97}\right)_{\mathrm{A}}$ & {$\left[\mathrm{Ni}_{0.4} \mathrm{Co}_{0.57} \mathrm{Fe}_{1.03}\right]_{\mathrm{B}}$} & $8.3349(5)$ & 8.3388 & $0.76(4)$ & $\begin{array}{l}\mathrm{R}_{\text {Bragg }}=3.96 \\
\mathrm{R}_{\mathrm{F}}=2.58 \\
\chi^{2}=2.89\end{array}$ \\
\hline 0.6 & $\left(\mathrm{Co}_{0.02} \mathrm{Fe}_{0.98}\right)_{\mathrm{A}}$ & {$\left[\mathrm{Ni}_{0.6} \mathrm{Co}_{0.38} \mathrm{Fe}_{1.02}\right]_{\mathrm{B}}$} & $8.3256(5)$ & 8.3251 & $0.59(4)$ & $\begin{array}{l}\mathrm{R}_{\text {Bragg }}=4.60 \\
\mathrm{R}_{\mathrm{F}}=3.03 \\
\chi^{2}=2.43\end{array}$ \\
\hline 0.8 & $\left(\mathrm{Ni}_{0.05} \mathrm{Fe}_{0.95}\right)_{\mathrm{A}}$ & {$\left[\mathrm{Ni}_{0.75} \mathrm{Co}_{0.2} \mathrm{Fe}_{1.05}\right]_{\mathrm{B}}$} & $8.3173(5)$ & 8.3209 & $0.64(4)$ & $\begin{array}{l}\mathrm{R}_{\text {Bragg }}=3.69 \\
\mathrm{R}_{\mathrm{F}}=2.97 \\
\chi^{2}=2.23\end{array}$ \\
\hline 1.0 & $\left(\mathrm{Ni}_{0.37} \mathrm{Fe}_{0.63}\right)_{\mathrm{A}}$ & {$\left[\mathrm{Ni}_{0.63} \mathrm{Fe}_{1.37}\right]_{\mathrm{B}}$} & $8.3075(5)$ & 8.3040 & $0.62(4)$ & $\begin{array}{l}\mathrm{R}_{\text {Bragg }}=3.86 \\
\mathrm{R}_{\mathrm{F}}=3.08 \\
\chi^{2}=2.53\end{array}$ \\
\hline
\end{tabular}


The total neutron diffraction data $\left(10^{\circ} \leq 2 \theta \leq 110^{\circ}\right)$ containing both nuclear and magnetic contributions were analyzed using the program FullProf in two different phases, the nuclear phase and the magnetic phase, using an additional space group $F-1$ for the magnetic phase. The occupation number of cations on both the A and B sites as determined from the higher angle neutron diffraction data were kept constant and all the other parameters were varied freely in this part of refinement. The symmetry operators for the magnetic atoms were supplied as external input to the program. Figure 3 shows a plot of the Reitveld refinement result of the total neutron diffraction data containing both nuclear and magnetic contributions for the composition $\mathrm{x}=0.8$. There is excellent agreement between the observed and calculated profiles in the nuclear and magnetic phases.

The neutron diffraction patterns at room temperature for different compositions in the $2 \theta$ range $15^{\circ}-70^{\circ}$ are shown in Figure 4. The intensity change in the Bragg peaks with increasing $x$, as evident from Figure 4, is a manifestation of the substitution effect in the system. A small fluctuation in the Bragg intensities is present but the position of the Bragg peaks does not show any significant change with increasing $\mathrm{x}$. Thus, the replacement of $\mathrm{Co}^{2+}$ ions by $\mathrm{Ni}^{2+}$ ions in these spinel oxides does not show any remarkable change in the lattice dimension. The spinel system under study consists of three different types of cations $\left(\mathrm{Ni}^{2+}, \mathrm{Co}^{2+}\right.$ and $\left.\mathrm{Fe}^{3+}\right)$ which are distributed over the A and B sites. The coherent scattering lengths of Ni, Co and Fe for neutrons are 10.30, 2.49 and $9.45 \mathrm{fm}$, respectively. The significant difference in the coherent scattering lengths is advantageous for the correct determination of cation occupancies. In the refinement process, initially $\mathrm{Ni}$ was kept fixed on the B sites, because it shows such site preferences [18] [19]. Then, occupancies of Co and Fe on the two sites were varied within the stoichiometric limit. Finally, the occupancy of Ni was varied separately with Co and Fe one by one.

From the refinement, it is observed that for $x \leq 0.6 \mathrm{Ni}$ ions invariably occupy the octahedral (16d) site only. For $\mathrm{x} \geq 0.8$, some Ni ions enter into the tetrahedral (8a) site and their occupation in this site gradually increases with increasing $\mathrm{x}$. On the other hand, Co ions are distributed over both 8a and 16d sites for the composition with $x \leq 0.6$, while all the Co ions enter into the $16 \mathrm{~d}$ site for $x \geq 0.8$. However, the occupation of Co gradually decreases in both the sites for all values of $x$. The Fe ions are distributed over both $8 \mathrm{a}$ (A) and 16d (B) sites for the whole compositional range investigated. The occupation of Fe increases in A site and decreases in $\mathrm{B}$ site for $\mathrm{x} \leq$ 0.6 , while it decreases in A site and increases in $B$ site for $x \geq 0.8$. The variation of the occupation factors of individual cations as a function of composition over the tetrahedral and octahedral sites are presented in Figure 5.

The lattice constants decreases and the oxygen position parameters increases with increasing Ni content (x) in the system. The dependence of the lattice parameter (a) and the oxygen position parameter (u) on Ni content (x) is shown in Figure 6. It is quite evident from the figure that the lattice parameter exhibits a linear dependence on $\mathrm{x}$ obeying the Vegard's law [22]. The decrease in the lattice parameter with Ni concentration could be attributed

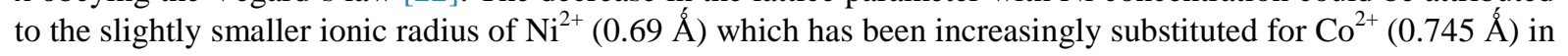
the system. The oxygen position parameter u lies within the normal limit of $0.25-0.27$ for the spinel oxides

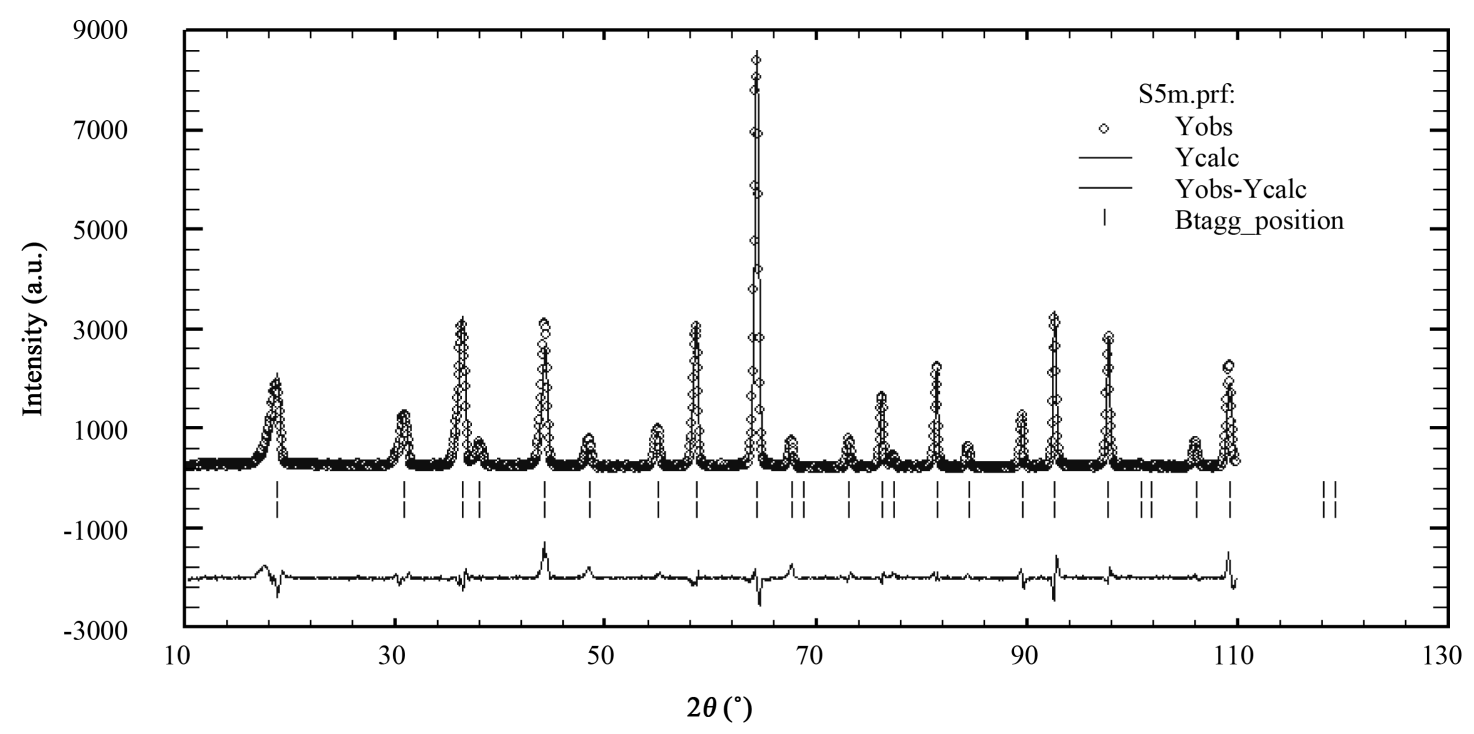

Figure 3. Fitted total neutron diffraction profiles comprising both nuclear and magnetic contributions for the composition $\mathrm{x}=8$. 


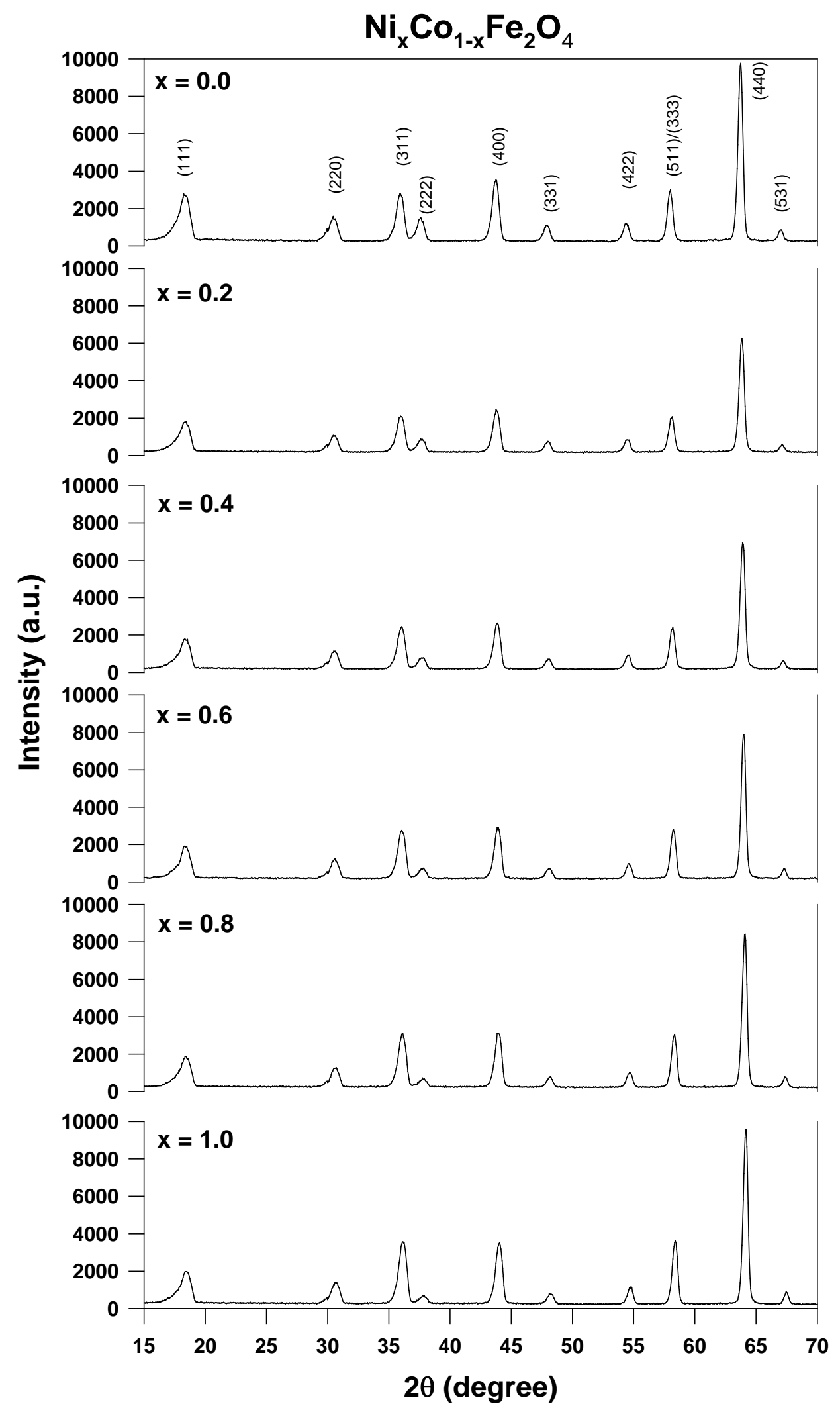

Figure 4. Neutron powder diffraction patterns of $\mathrm{Ni}_{\mathrm{x}} \mathrm{Co}_{1-{ }_{-}} \mathrm{Fe}_{2} \mathrm{O}_{4}$ for the compositions $\mathrm{x}=0.0,0.2$, $0.4,0.6,0.8$ and 1.0 at room temperature. 


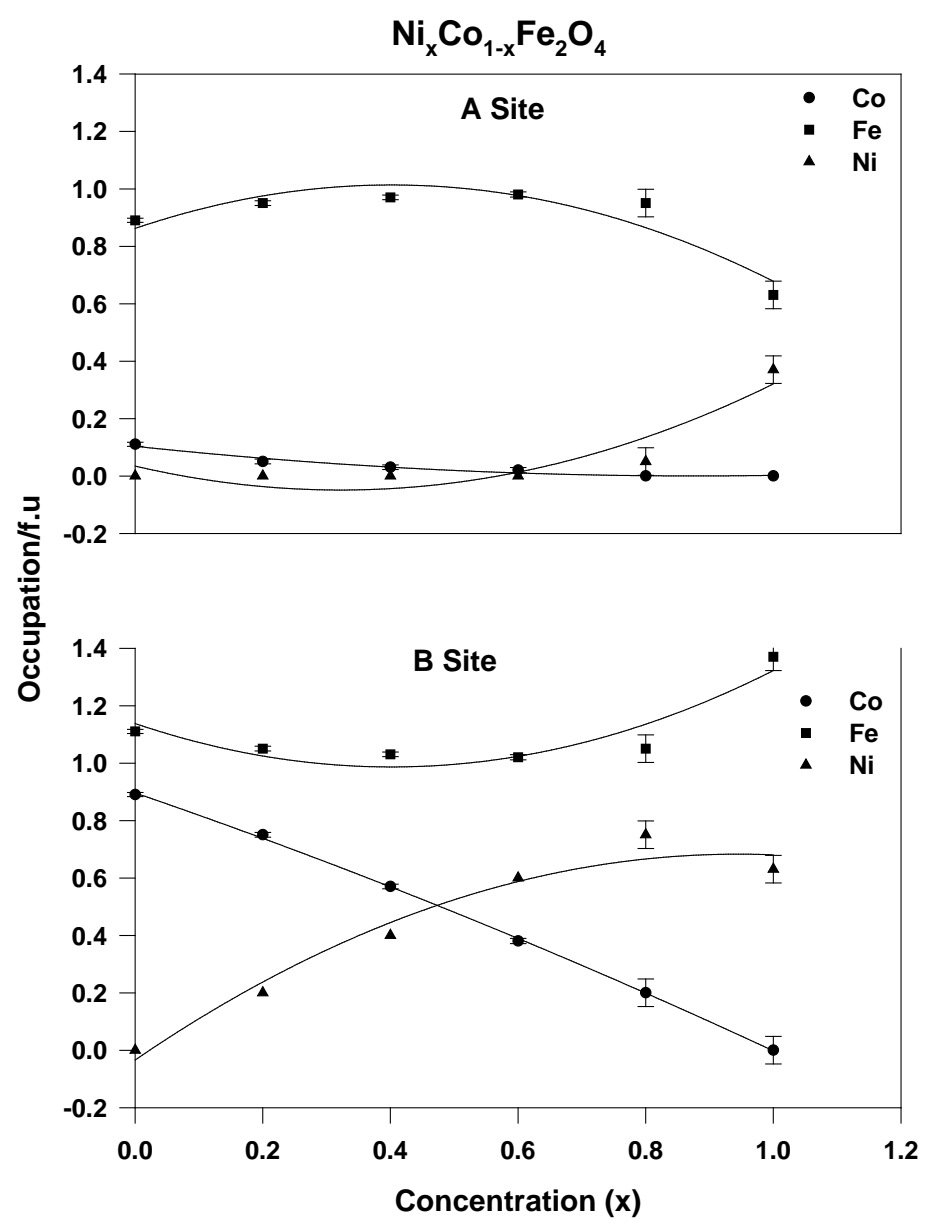

Figure 5. Variation of cation occupation factors with composition, $x$. The solid line represents the regression fit to the experimental data.

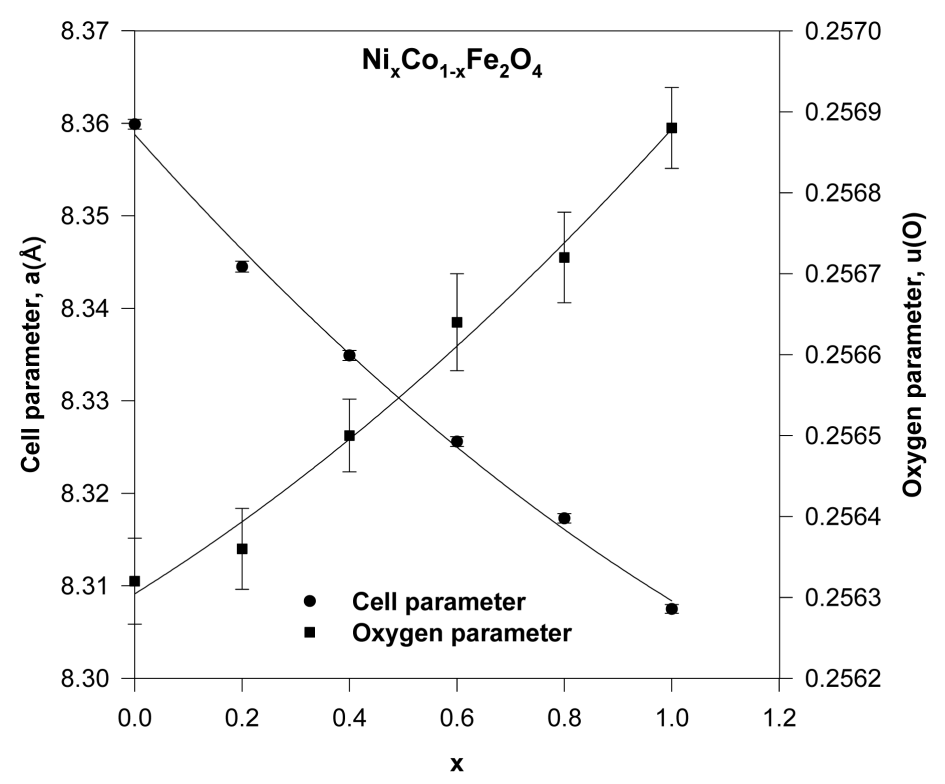

Figure 6. Dependence of the cell parameter, $a(\AA)$ and oxygen position parameter, $\mathrm{u}(\mathrm{O})$ on $\mathrm{x}$. 
showing linear concentration dependence (Figure 6).

The tetrahedral and octahedral cation-anion bond distances $d_{\mathrm{A}-\mathrm{O}}$ and $d_{\mathrm{B}-\mathrm{O}}$ have been calculated using the Piox data [23] [24]: $d_{\mathrm{A}-\mathrm{O}}\left(\mathrm{Ni}^{2+}-\mathrm{O}\right)=1.970 \AA, d_{\mathrm{B}-\mathrm{O}}\left(\mathrm{Ni}^{2+}-\mathrm{O}\right)=2.088 \AA ; d_{\mathrm{A}-\mathrm{O}}\left(\mathrm{Co}^{2+}-\mathrm{O}\right)=1.967 \AA, d_{\mathrm{B}-\mathrm{O}}\left(\mathrm{Co}^{2+}-\mathrm{O}\right)=2.131$ $\AA$ and $d_{\mathrm{A}-\mathrm{O}}\left(\mathrm{Fe}^{3+}-\mathrm{O}\right)=1.855 \AA, d_{\mathrm{B}-\mathrm{O}}\left(\mathrm{Fe}^{3+}-\mathrm{O}\right)=2.020 \AA$. Since there are more than one kind of ions present in each site the weighted mean values of bond distances have been calculated using the cation distribution obtained from the Rietveld refinement of our neutron diffraction data listed in Table 1. The mean values of A-O and B-O bond distances have been obtained from the output of the Rietveld refinement of experimental neutron diffraction data. The calculated bond distances from Piox data are compared with those obtained from the refinement of experimental data in Table 2.

The deviation in the A-O bond lies in the range $0.26 \%-2.15 \%$ while that in the B-O bond ranges from $1.47 \%$ $1.70 \%$. It is quite obvious from the table that the values of experimental A-O and B-O bond distances decrease with increasing $\mathrm{x}$. As before, this may be explained as an effect of the substitution of slightly smaller Ni ions for Co ions in the system. However, the calculated bond distance on the tetrahedral site decreases upto $\mathrm{x} \geq 0.6$ and then increases depending on the cations occupied in this site, while on the octahedral site it decreases with increasing $\mathrm{x}$ for the whole compositional range investigated. This result indicates that the Piox data may not be suitable for describing the cation-anion distance in the present system where many different types of cations are present at the same site with various dimensions and concentrations.

In the spinel structure, the relation between lattice parameter and bond distances is expressed as [25]:

$$
a=\frac{8}{9}\left(\sqrt{3} d_{\mathrm{A}-\mathrm{O}}+3 d_{\mathrm{B}-\mathrm{O}}\right)
$$

where $d_{\mathrm{A}-\mathrm{O}}$ and $d_{\mathrm{B}-\mathrm{O}}$ are the average cation-anion bond lengths of A and B site respectively. Using the above relation, the lattice parameters are also calculated and compared with those obtained from Rietveld refinement of neutron diffraction data in Table 1. The maximum deviation found between the experimental and calculated lattice parameters is less than $0.1 \%$.

In spinel oxides, the magnetic moments are mainly from the parallel uncompensated electron spins of the individual ions and according to Néel's two sublattice model, the spin alignments in the two sublattices are antiparallel. The net magnetic moments per formula unit, $\mathrm{n}_{\mathrm{B}}$ is expressed as: $\mathrm{n}_{\mathrm{B}}=M_{\mathrm{B}}-M_{\mathrm{A}}$, where $M_{\mathrm{A}}$ and $M_{\mathrm{B}}$ are tetrahedral and octahedral sublattice magnetic moments in $\mu_{\mathrm{B}}$, respectively. In spinels, the magnetic and crystallographic unit cells and the associated symmetry relations are the same. Therefore, both the nuclear and magnetic scattering contributions to the Bragg peaks occur at the same scattering angles giving rise to an enhanced intensity. In order to take the magnetic contribution to the Bragg diffraction peaks into account, the neutron diffraction data in the entire angular range for each member of the series were refined with an additional phase for the magnetic part (Figure 3). The sublattices and net magnetization obtained from the two-phase refinement of the room temperature neutron diffraction data have been plotted in Figure 7. Significant magnetic moments have been deduced from the refinement of neutron diffraction data from all the compositions indicating that the system possess ferrimagnetic ordering at room temperature. From the figure it is observed that the B site moments decrease slightly with increasing $\mathrm{x}$, where as the A site moments vary within the error limit and remain almost

Table 2. Comparison of cation-anion bond distances $d_{\mathrm{A}-\mathrm{O}}(\AA)$ and $d_{\mathrm{B}-\mathrm{O}}(\AA)$ as obtained from the analysis of experimental data with those calculated from Poix data for the spinel system $\mathrm{Ni}_{\mathrm{x}} \mathrm{Co}_{1-\mathrm{x}} \mathrm{Fe}_{2} \mathrm{O}_{4} \cdot \Delta d_{\mathrm{A}-\mathrm{O}}$ and $\Delta d_{\mathrm{B}-\mathrm{O}}$ are the deviations between the experimental and calculated Piox bond distances in the tetrahedral and octahedral site, respectively.

\begin{tabular}{|c|c|c|c|c|c|c|}
\hline \multirow{2}{*}{$\mathrm{x}$} & \multicolumn{2}{|c|}{$d_{\mathrm{A}-\mathrm{O}}(\AA)$} & \multirow{2}{*}{$\Delta d_{\mathrm{A}-\mathrm{O}}(\%)$} & \multicolumn{2}{|c|}{$d_{\mathrm{B}-\mathrm{O}}(\AA)$} & \multirow{2}{*}{$\Delta d_{\mathrm{B}-\mathrm{O}}(\%)$} \\
\hline & Experimental & Piox & & Experimental & Piox & \\
\hline 0.0 & $1.9051(5)$ & 1.8673 & 2.02 & $2.0365(4)$ & 2.0694 & 1.62 \\
\hline 0.2 & $1.8986(6)$ & 1.8606 & 2.04 & $2.0344(5)$ & 2.0684 & 1.67 \\
\hline 0.4 & $1.8984(6)$ & 1.8584 & 2.15 & $2.0310(5)$ & 2.0652 & 1.68 \\
\hline 0.6 & $1.8963(7)$ & 1.8572 & 2.11 & $2.0271(6)$ & 2.0615 & 1.70 \\
\hline 0.8 & $1.8939(7)$ & 1.8608 & 1.78 & $2.0269(6)$ & 2.0566 & 1.47 \\
\hline 1.0 & $1.8926(7)$ & 1.8976 & 0.26 & $2.0213(6)$ & 2.0550 & 1.67 \\
\hline
\end{tabular}




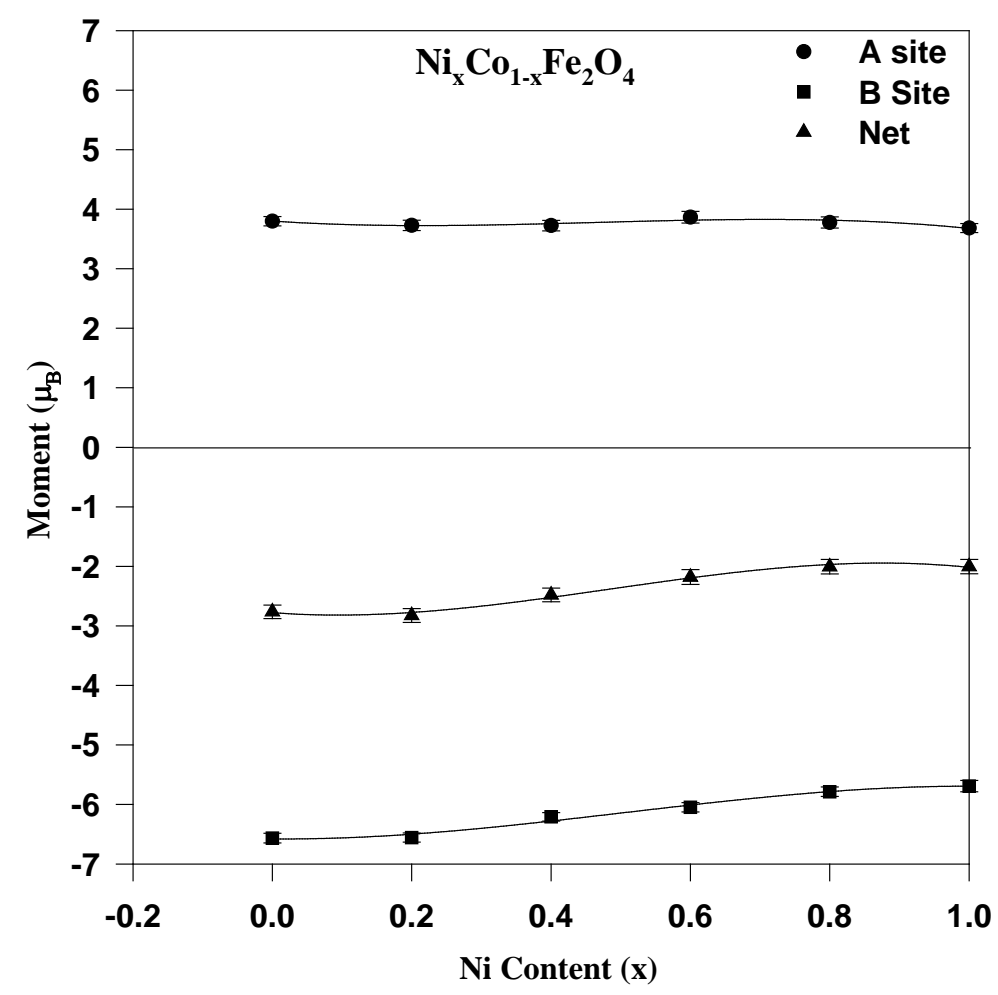

Figure 7. Plots of the sublattices and net magnetic moments with $\mathrm{x}$ for the spinel system $\mathrm{Ni}_{\mathrm{X}} \mathrm{Co}_{1-\mathrm{X}} \mathrm{Fe}_{2} \mathrm{O}_{4}$ at room temperature.

the same throughout the compositional range investigated. The net moments decrease slightly with increasing $\mathrm{x}$ in the system.

\section{Conclusion}

The ferrite system $\mathrm{Ni}_{\mathrm{x}} \mathrm{Co}_{1-\mathrm{x}} \mathrm{Fe}_{2} \mathrm{O}_{4}(\mathrm{x}=0.0,0.2,0.4,0.6,0.8$ and 1.0) synthesized in the conventional solid state sintering technique in air has been characterized to be polycrystalline single phase cubic spinel belonging to the space group $F d-3 m$. The final sintering temperature, as determined by trial and error method, is found to be $1300^{\circ} \mathrm{C}$ in air. The neutron diffraction measurements have given a clear picture of the distribution of cations for each member of the series having three different types of cations of which some of them are very close in atomic number. The occupation numbers of different cations over the A and B sites have been determined precisely since this technique is capable of differentiating them due to the large variation of the scattering length of these atoms for neutron. For all the compositions, Fe ions are distributed over both A and B sites. Ni ions invariably occupy the octahedral (16d) site only for $\mathrm{x} \leq 0.6$, while Co ions are distributed in both A and B sites for this compositional range. For $\mathrm{x} \geq 0.8$, some Ni ions enter into the tetrahedral (A) site, while all the Co ions enter into the octahedral (B) site. The knowledge of the cation distribution will be helpful in determining the magnetic and other properties of the system. The deduced sublattice and net moments reveal the system exhibited ferrimagnetic ordering at room temperature for the whole range of composition studied. In order to know the detailed magnetic behavior of the system, temperature dependent neutron diffraction studies will be performed and reported later on.

\section{Acknowledgements}

One of the author (Sadia Khanam) are grateful to the Reactor and Neutron Physics Division (RNPD), Institute of Nuclear Science \& Technology (INST) and Reactor Operation and Maintenance Unit (ROMU), Atomic Energy Research Establishment (AERE), Bangladesh Atomic Energy Commission (BAEC), Savar, Dhaka for the support in order to carry out this research work. 


\section{References}

[1] Pardavi-Horvath, M. (2000) Microwave Application of Soft Ferrites. Journal of Magnetism and Magnetic Materials, 215-216, 171-183. http://dx.doi.org/10.1016/S0304-8853(00)00106-2

[2] Ruiz, M.S., Bercoff, P.G. and Jacobo, S.E. (2013) Sheilding Properties of CuNiZn Ferrite in the Radio Frequency Range. Ceramics International, 39, 4777-4782. http://dx.doi.org/10.1016/j.ceramint.2012.11.067

[3] Kkalaj-Amirhosseini, M. (2006) Microwave Filters Using Waveguides Filled by Multilayer Dielectric. Progress in Electromagnetics Research, 66, 105-110. http://dx.doi.org/10.2528/PIER06102502

[4] Saed, M.A. and Yadla, R. (2006) Microstrip-Fed Low Profile and Compact Dielectric Resonator Antennas. Progress in Electromagnetics Research, 56, 151-162. http://dx.doi.org/10.2528/PIER05041401

[5] Pasquale, M., Sasso, C.P., Velluto, M. and Lim, S.H. (2002) Stress Sensing with Co Based Ferrite Composites. Journal of Magnetism and Magnetic Materials, 242, 1460-1463. http://dx.doi.org/10.1016/S0304-8853(01)01103-9

[6] Amiri, G.R., Yousefi, M.H., Abolhassani, M.R., Manouchehri, S., Keshavarz, M.H. and Fatahian, S. (2011) Magnetic Properties and Microwave Absorption in Ni-Zn and Mn-Zn Ferrite Nonoparticles Synthesized by Low-Temperature Solid-State Reaction. Journal of Magnetism and Magnetic Materials, 323, 730-734. http://dx.doi.org/10.1016/j.jmmm.2010.10.034

[7] Yallapu, M.M., Othman, S.F., Curtis, E.T., Gupta, B.K., Jaggi, M. and Chauhan, S.C. (2011) Multifunctional Magnetic Nanoparticles for Magnetic Resonance Imaging and Cancer Therapy. Biomaterials, 32, 1890-1905. http://dx.doi.org/10.1016/j.biomaterials.2010.11.028

[8] Zakaria, A.K.M., Asgar, M.A., Eriksson, S.-G., Ahmed, F.U., Yunus, S.M. and Rundlöf, H. (2003) The Study of Magnetic Ordering in the Spinel System $\mathrm{Zn}_{\mathrm{x}} \mathrm{Ni}_{1-\mathrm{x}} \mathrm{FeCrO}_{4}$ by Neutron Diffraction. Journal of Magnetism and Magnetic Materials, 265, 311-320. http://dx.doi.org/10.1016/S0304-8853(03)00280-4

[9] Zakaria, A.K.M. and Asgar, M.A. (2005) Studies of the Magnetic Ordering in the Spinel System $\mathrm{Zn}_{0.4} \mathrm{Co}_{0.6} \mathrm{Al}_{\mathrm{x}} \mathrm{Fe}_{2-\mathrm{x}} \mathrm{O}_{4}$ by Neutron Diffraction. Journal of Alloys and Compounds, 396, 44-53. http://dx.doi.org/10.1016/j.jallcom.2004.12.022

[10] Nesa, F., Zakaria, A.K.M., Khan, M.A.S., Yunus, S.M., Das, A.K., Eriksson, S.-G., Khan, M.N.I., Saha, D.K. and Hakim, M.A. (2012) Structural and Magnetic Properties of $\mathrm{Cr}^{3+}$ Doped Mg Ferrites. World Journal of Condensed Matter Physics, 2, 27-35. http://dx.doi.org/10.4236/wjcmp.2012.21005

[11] Akter, S., Paul, D.P., Hakim, M.A., Saha, D.K., Al-Mamun, M. and Parveen, A. (2011) Synthesis, Structural and Physical Properties of $\mathrm{Cu}_{1-\mathrm{x}} \mathrm{Zn}_{\mathrm{x}} \mathrm{Fe}_{2} \mathrm{O}_{4}$ Ferrites. Materials Sciences and Applications, 2, 1675-1681. http://dx.doi.org/10.4236/msa.2011.211223

[12] Hoque, S.M., Choudhury, M.A. and Islam, M.F. (2002) Characterization of Ni-Cu Mixed Spinel Ferrites. Journal of Magnetism and Magnetic Materials, 251, 292-303. http://dx.doi.org/10.1016/S0304-8853(02)00700-X

[13] Akther Hossain, A.K.M., Mahmud, S.T., Seki, M., Kawai, T. and Tabata, H. (2007) Structural, Electrical Transport and Magnetic Properties of $\mathrm{Ni}_{1-\mathrm{x}} \mathrm{Zn}_{\mathrm{x}} \mathrm{Fe}_{2} \mathrm{O}_{4}$. Journal of Magnetism and Magnetic Materials, 312, 210-219. http://dx.doi.org/10.1016/j.jmmm.2006.09.030

[14] Xu, C. (2001) Magnetic and Microwave Absorption Properties of $\mathrm{Ni}_{1-\mathrm{x}} \mathrm{Co}_{\mathrm{x}} \mathrm{Fe}_{2} \mathrm{O}_{4}$ Nanometer Powders in GHz Frequencies. Materials Science Forum, 694, 380-384. http://dx.doi.org/10.4028/www.scientific.net/MSF.694.380

[15] Liu, B.H., Ding, J., Yi, J.B., Yin, J.H. and Dong, Z.L. (2008) Magnetic Anisotopies in Cobalt Nickel Ferrites. Journal of the Korean Physical Society, 52, 1483-1486. http://dx.doi.org/10.3938/jkps.52.1483

[16] Yunus, S.M., Yamauchi, H., Zakaria, A.K.M., Igawa, N., Hoshikawa, A. and Ishii, Y. (2008) Cation Distribution and Crystallographic Characterization of the Quaternary Spinel System $\mathrm{Mg}_{\mathrm{x}} \mathrm{Co}_{1_{-} \mathrm{x}} \mathrm{Cr}_{\mathrm{x}} \mathrm{Fe}_{2-\mathrm{x}} \mathrm{O}_{4}$. Journal of Alloys and Compounds, 454, 10-15. http://dx.doi.org/10.1016/j.jallcom.2006.12.022

[17] Ghatage, A.K., Patil, S.A. and Paranjpe, S.K. (1996) Neutron Diffraction Study of Chromium Substituted Nickel Ferrite. Solid State Communications, 98, 885-888. http://dx.doi.org/10.1016/0038-1098(96)00036-1

[18] Yunus, S.M., Fernandez-Baca, J.A., Asgar, M.A., Ahmed, F.U. and Hakim, M.A. (1999) Neutron Diffraction Studies of the Magnetic Disorder in $\mathrm{Zn}_{\mathrm{x}} \mathrm{Mg}_{0.8-\mathrm{x}} \mathrm{Ni}_{0.2} \mathrm{Fe}_{2} \mathrm{O}_{4}$ Ferrite with $\mathrm{x}=0.0,0.2,0.4$ and 0.6. Physica B, 262, 112-124. http://dx.doi.org/10.1016/S0921-4526(98)00655-3

[19] Zakaria, A.K.M., Asgar, M.A., Eriksson, S.G., Ahmed, F.U., Yunus, S.M., Azad, A.K. and Rundlof, H. (2003) Preparation of Zn Substituted Ni-Fe-Cr Ferrites and Study of the Crystal Structure by Neutron Diffraction. Materials Letters, 57, 4243-4250. http://dx.doi.org/10.1016/S0167-577X(03)00298-2

[20] Rodriguez-Carvajal, J. (1993) Recent Advances in Magnetic Structure Determination by Neutron Powder Diffraction. Physica B, 192, 55-69. http://dx.doi.org/10.1016/0921-4526(93)90108-I

[21] Rietveld, H.M. (1969) A Profile Refinement Method for Nuclear and Magnetic Structures. Journal of Applied Crystallography, 2, 65-71. http://dx.doi.org/10.1107/S0021889869006558

[22] Vegard, L. (1921) Zeitchrift for Physik a Hadrons and Nuclei. Physics and Astronomy, 5, 17-26. 
[23] Piox, P. (1965) Sur une méthode de détermination des distances cation-oxygéne dans les oxides mixtes à structure spinelle, Application des valeurs à quelques cas particuliers. Bulletin de la Société Chimique de France, 5, 1085-1087.

[24] Piox, P. (1969) Chime Minérale. Table générale des distances caractéristiques “métal-oxygéne” en coordinate 6. Comptes Rendus de l'Académie des Sciences Paris, Série C, 268, 1139-1140.

[25] Krupicka, S. and Novak, P. (1982) In: Wohlfarth, E.P., Ed., Ferromagnetic Materials, Vol. 3, North-Holland, Amsterdam. 